\title{
Analisis Penerapan Target Costing dalam Upaya Pengendalian Biaya Produksi pada CV Multi Bangunan
}

\author{
Beta Maya Alvio Dinda1, Yulinartati ${ }^{2}$, Astrid Maharani ${ }^{3}$ \\ 1,2,3 Program Studi Akuntansi Universitas Muhammadiyah Jember, Indonesia
}

\begin{abstract}
Keywords: Abstract: Companies have difficulty in maximizing profits. One of the reasons why companies find Target costing it difficult to develop is that they still use traditional methods in their operations. The purpose of this study was to determine the application of target costing applied to CV. Multi Buildings in controlling production costs. The type of research used in this research is descriptive qualitative. The data obtained in this study were based on primary data in the form of interviews and observations, and based on secondary data in the form of documentation. The results of the study concluded that the target costing method is a good method in controlling costs, the target costing method can help management to redesign the product by considering costs, product quality, and profit to be achieved. The target costing method is a good alternative to reduce costs, it can be seen that the production cost before the implementation of target costing ranges from Rp. $344,772,000$ to Rp. $754,115,066$ in one year. The use of the target costing method has a positive impact on profit achievement, the achievement of profit before the implementation of target costing ranges from Rp. 15,000 to $\mathrm{Rp} .19,000$ per $\mathrm{m} 2$ and the achievement of profit after the implementation of target costing ranges from Rp. 17,000 to Rp. 27,000 per $\mathrm{m} 2$. Thus, the target costing method proved to have a positive impact on the achievement of company profits.

Abstrak: Perusahaan mengalami kesulitan dalam memaksimalkan laba. Salah satu penyebab perusahaan sulit berkembang yaitu masih menggunakan metode tradisional dalam kegiatan operasionalnya. Tujuan penelitian ini adalah untuk mengetahui penerapan target costing yang

Kata

kunci:

Target

costing diterapkan pada CV Multi Bangunan dalam pengendalian biaya produksi. Jenis penelitian adalah deskriptif kualitatif. Data yang diperoleh dalam penelitian ini berdasarkan data primer yang berupa wawancara dan observasi serta data sekunder yang berupa dokumentasi. Hasil penelitian menunjukkan bahwa metode target costing merupakan metode yang baik dalam pengendalian biaya. Metode target costing dapat membantu manajemen untuk mendesain ulang produk dengan mempertimbangkan biaya, kualitas produk, dan laba yang akan dicapai. Metode target costing merupakan alternatif yang baik untuk menekan biaya. Hal ini dapat diketahui dari biaya produksi sebelum diterapkannya target costing berkisar dari $\mathrm{Rp} 344.772 .000$ sampai $\mathrm{Rp} 754.115 .066$ dalam satu tahun. Penggunaan metode target costing berdampak positif dalam pencapaian laba. Pencapaian laba sebelum diterapkannya target costing berkisar antara Rp 15.000 sampai Rp 19.000 per $\mathrm{m} 2$, sedangkan pencapaian laba setelah diterapkannya target costing berkisar antara Rp 17.000 sampai Rp 27.000 per $\mathrm{m} 2$. Ini berrati bahwa metode target costing terbukti berdampak positif dalam pencapaian laba perusahaan.
\end{abstract}

\section{Alamat Korespondensi:}

E-mail: alviodindabetamaya@gmail.com (Dinda)

\section{Pendahuluan}

Persaingan di dunia industri guna menghasilkan suatu produk yang berkualitas saat ini semakin berkembang pesat (Biodi \& Sanawiri, 2017; Dirgayusa \& Suardikha, 2017). Perkembangan dunia industri saat ini dipengaruhi oleh semakin maju teknologi dan pemanfaatannya. Agar dapat bertahan berkembang di dunia industri, perusahaan harus mampu menghasilkan produksi yang berkualitas (Hermawan, 2018; Hoyt \& Liebenberg, 2011). Secara umum tujuan perusahaan adalah untuk menghasilkan produksi atau jasa yang dibutuhkan oleh masyarakat untuk dapat

$\begin{array}{ll}\text { History: } & \\ \text { Received } & \text { : 25 Januari } 2021 \\ \text { Revised } & : \text { 28 Januari } 2021 \\ \text { Accepted } & \text { : 06 April } 2021 \\ \text { Published } & \text { : 25 Juli } 2021\end{array}$

Publisher: Undiksha Press

Licensed: This work is licensed under a Creative Commons Attribution 3.0 License

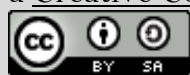


memaksimalkan nilai perusahaan dan dapat mempertahankan keberlangsungan hidup perusahaan di masa yang akan datang (Arifin et al., 2012; Salam, 2020) (Husnan, 1993). Perlu adanya kebijakan yang ditetapkan oleh perusahaan agar dapat mencapai laba yang maksimal. Kebijakan yang diterapkan dapat berupa perencanaan pengendalian biaya produksi (Biodi \& Sanawiri, 2017; Kasus et al., 2021). Kebijakan dalam pengendalian biaya produksi secara umum merupakan suatu strategi bagi perusahaan dalam merencanakan biaya produksi yang sesuai dalam rangka efisiensi dan efektivitas biaya (Juwita \& Satria, 2017; Wokas \& Caroline, 2016). Apabila terjadi perubahan-perubahan dukungan, maka diperlukan metode yang ideal sesuai dengan kondisi pasar dan kondisi perusahaan, sehingga perusahaan tetap memperoleh laba dan dapat mencapai tujuannya.

Permasalahan lain yang dihadapi perusahaan yaitu kesulitan dalam memaksimalkan laba. Salah satu penyebab perusahaan sulit berkembang yaitu masih menggunakan metode tradisional dalam kegiatan operasionalnya (Febriana, 2020; Muhyiddin, 2020). Selain itu, penggunaan metode tradisional membuat perusahaan kesulitan memaksimalkan laba, sehingga sulit untuk mencapai target laba yang diharapkan (Juwita \& Satria, 2017; Nailufar et al., 2018). Kekurangan metode tradisional yaitu tidak memasukkan unsur konsumen pada saat proses penetapan harga. Selain itu, metode ini bersifat statis dan tidak melihat kondisi pasar. Dalam persaingan yang semakin ketat dan dinamis, perusahaan dituntut untuk terus berusaha menemukan solusi yang dapat membantu mereka dari waktu ke waktu. Oleh karena itu, perusahaan membutuhkan metode manajemen biaya modern yang dapat membantu mereka menghadapi persaingan dan mencapai tujuan dalam memaksimalkan laba.

Solusi yang dapat dilakukan yaitu dengan menggunakan metode tertentu. Salah satu metode yang dapat digunakan yaitu metode target costing. Metode target costing merupakan metode yang penentuan biayanya didasarkan pada perencanaan harga jual dan laba yang diinginkan oleh perusahaan (Anugerah et al., 2017; Wokas \& Caroline, 2016). Target costing diperlukan untuk mengurangi biaya (cost reducation) agar dapat mencapai tujuan perusahaan yang pada akhirnya akan berdampak pada tingkat harga yang kompetitif (Darmayasa et al., 2019; Mahsunah \& Hariyati, 2021). Penerapan target costing pada suatu perusahaan juga harus memerhatikan hal-hal yang berkaitan dengan keberhasilan implementasi dari adanya inovasi tersebut. Target costing adalah salah satu di antara alat-alat yang digunakan untuk industri-industri agar dapat mencegah penentuan harga jual yang keliru dan membantu pengembangan produk lebih cepat dan lebih terfokus. Penggunaan target costing dapat dilakukan dengan alasan-alasan yakni banyak perusahaan yang melakukan kurang kontrol atas harga sebagaimana yang mereka pikirkan. Observasi merupakan komponen biaya yang terbesar dari suatu produk tahap desain (Mahsunah \& Hariyati, 2021; Wokas \& Caroline, 2016). Dengan target costing dibuat terlebih dahulu dan kemudian produk didesain, sehingga biaya menjadi strandar yang harus dicapai.

Temuan penelitian sebelumnya menyatakan metode target costing berdampak pada peningkatan laba (Darmayasa et al., 2019; Febriana, 2020). Adanya metode target costing, laba yang didapatkan lebih optimal karena drifting cost yang dihasilkan lebih kecil (Juwita \& Satria, 2017; Mahsunah \& Hariyati, 2021). Dengan penerapan target costing, biaya produksi bisa diefisiensikan dan peningkatan laba yang diperoleh pun cukup signifikan (Anugerah et al., 2017; Wokas \& Caroline, 2016). Kajian sebelumnya dilakukan pada berbagai perusahaan maupun UMKM. Metode target costing ini belum pernah diterapkan pada CV Multi Bangunan. Tujuan penelitian ini yaitu menganalisis penerapan target costing dalam upaya pengendalian biaya produksi pada CV Multi Bangunan.

\section{Metode}

Jenis penelitian yang digunakan dalam penelitian ini adalah deskriptif kualitatif. Jenis data yang digunakan dalam penelitian ini yaitu data dokumenter. Data dokumenter dalam penelitian ini dapat menjadi bahan atau dasar analisis data yang kompleks dengan dikumpulkan melalui metode observasi dan analisis dokumen. Sumber data dalam penelitian ini menggunakan dua sumber, yaitu data primer dan data sekunder. Data primer merupakan data yang diperoleh berdasarkan 
waawancara dan observasi langsung ke perusahaan dengan tujuan mendapatkan data yang akurat dalam penelitian ini. Data sekunder umumnya berupa bukti, catatan atau laporan historis yang telah tersusun dalam arsip (data dokumenter) yang dipublikasikan dan yang tidak dipublikasikan (Indriantoro dan Supomo, 2014). Dalam penelitian ini data sekunder berupa bukti transaksi pengeluaran biaya produksi. Dalam penelitian ini, data dan informasi yang diperoleh, dikumpulkan melalui tahap-tahap penelitian kepustakaan, pengamatan/observasi, wawancara, dan dokumentasi.

Teknik analisis data pada penelitian ini dimulai dengan mengumpulkan data dari perusahaan mengenai biaya pokok produksi, menentukan target laba yang diharapkan oleh perusahaan, menentukan target costing, menghitung drifting cost, melakukan value engeneering pada biaya yang berlebih, dan menganalisis biaya produksi jika metode target costing diterapkan pada perusahaan. Pada penelitian kali ini objek penelitian hanya menggunakan beberapa produk yang terdapat di CV Multi Bangunan yang banyak diminati oleh konsumen. Produk yang digunakan pada penelitian ini adalah paving segi-6, paving segi-4, paving conblock bata, dan paving diamond.

\section{Hasil dan Pembahasan}

\section{Hasil Penelitian}

Analisis biaya produksi pada CV Multi Bangunan adalah sebagi berikut. Biaya produksi yang dikeluarkan oleh perusahaan berupa biaya bahan baku, biaya tenaga kerja langsung, dan biaya overhead pabrik. Biaya overhead pabrik meliputi biaya pemeliharaan mesin, biaya penyusutan bangunan, biaya penyusutan mesin, biaya listrik, biaya bahan penolong, dan biaya tenaga kerja tidak langsung. Berikut merupakan biaya produksi untuk paving segi-6, paving segi-4, paving conblock bata, dan paving diamond pada CV Multi Bangunan.

Tabel 1. Biaya Produksi Paving Segi-6

\begin{tabular}{|c|c|}
\hline Keterangan & Jumlah \\
\hline Biaya Bahan Baku & Rp 138.037.500 \\
\hline Biaya Tenaga Kerja & Rp 137.700.000 \\
\hline \multicolumn{2}{|l|}{ Biaya Overhead Pabrik: } \\
\hline - Biaya pemeliharaan mesin & $\mathrm{Rp} \quad 3.090 .000$ \\
\hline - $\quad$ Biaya penyusutan bangunan & 984.000 \\
\hline - $\quad$ Biaya penyusutan mesin & $\mathrm{Rp} \quad 4.300 .000$ \\
\hline - Biaya lisrik & $\operatorname{Rp} \quad 1.719 .500$ \\
\hline - Biaya bahan penolong & $\mathrm{Rp} \quad 34.941 .000$ \\
\hline - $\quad$ Biaya tenaga kerja tidak langsung & Rp 24.000 .000 \\
\hline r r & Rp 344.772.000 \\
\hline Jumlah produk yang dihasilkan & $9.794 \mathrm{~m}^{2}$ \\
\hline Biaya produksi per $\mathrm{m}^{2}$ & Rp 35.000 \\
\hline Laba per $\mathbf{m}^{2}$ & Rp 15.000 \\
\hline
\end{tabular}

Sumber: CV. Multi Bangunan

Tabel 2. Biaya Produksi Paving Segi-4

\begin{tabular}{|c|c|c|}
\hline Keterangan & Jumlah & \\
\hline Biaya Bahan Baku & $\mathrm{Rp} 2$ & 16.389 .750 \\
\hline Biaya Tenaga Kerja & $\mathrm{Rp}$. & 60.650 .000 \\
\hline \multicolumn{3}{|l|}{ Biaya Overhead Pabrik } \\
\hline - Biaya pemeliharaan mesin & $\mathrm{Rp}$ & 4.000 .000 \\
\hline - Biaya penyusutan bangunan & $\mathrm{Rp}$ & 1.428 .000 \\
\hline - Biaya penyusutan mesin & $\mathrm{Rp}$ & 4.300 .000 \\
\hline - Biaya lisrik & $\mathrm{Rp}$ & 2.479 .700 \\
\hline
\end{tabular}




\begin{tabular}{|c|c|c|c|}
\hline \multicolumn{2}{|r|}{ Keterangan } & \multicolumn{2}{|l|}{ Jumlah } \\
\hline- & Biaya bahan penolong & $\mathrm{Rp}$ & 58.698 .030 \\
\hline \multicolumn{2}{|r|}{ - $\quad$ Biaya tenaga kerja tidak langsung } & $\mathrm{Rp}$ & 24.000 .000 \\
\hline & Total & $\operatorname{Rp} 4$ & 147.205.730 \\
\hline & Jumlah produk yang dihasilkan & & $14.200 \mathrm{~m}^{2}$ \\
\hline & Biaya produksi per $\mathrm{m}^{2}$ & & $\mathrm{Rp} 31.000$ \\
\hline & Laba per $\mathrm{m}^{2}$ & & $\mathrm{Rp} 19.000$ \\
\hline
\end{tabular}

Sumber: CV. Multi Bangunan

Tabel 3. Biaya Produksi Paving Conblock Bata

\begin{tabular}{|c|c|c|c|}
\hline \multicolumn{2}{|r|}{ Keterangan } & \multicolumn{2}{|c|}{ Jumlah } \\
\hline Biaya & ahan Baku & $\mathrm{Rp}$ & 29.562 .500 \\
\hline Biaya & enaga Kerja & Rp & 75.400 .000 \\
\hline \multicolumn{4}{|c|}{ Biaya Overhead Pabrik: } \\
\hline- & Biaya pemeliharaan mesin & $\mathrm{Rp}$ & 4.250 .000 \\
\hline- & Biaya penyusutan bangunan & $\mathrm{Rp}$ & 2.634 .000 \\
\hline- & Biaya penyusutan mesin & Rp & 3.700 .000 \\
\hline- & Biaya lisrik & $\mathrm{Rp}$ & 4.126 .800 \\
\hline- & Biaya bahan penolong & $\mathrm{Rp}$ & 58.279 .765 \\
\hline \multicolumn{2}{|r|}{ - $\quad$ Biaya tenaga kerja tidak langsung } & $\mathrm{Rp}$ & 24.000 .000 \\
\hline & Total & Rp & 54.115 .066 \\
\hline & Jumlah produk yang dihasilkan & & $26.190 \mathrm{~m}^{2}$ \\
\hline & Biaya produksi per $\mathrm{m}^{2}$ & & $\operatorname{Rp} 28.700$ \\
\hline & Laba per $\mathrm{m}^{2}$ & & Rp 16.300 \\
\hline
\end{tabular}

Tabel 4. Biaya Produksi Paving Diamond

\begin{tabular}{|c|c|c|}
\hline Keterangan & Jumlah & \\
\hline Biaya Bahan Baku & $\operatorname{Rp} 1$ & 152.620 .600 \\
\hline Biaya Tenaga Kerja & $\operatorname{Rp} 1$ & 137.700 .000 \\
\hline \multicolumn{3}{|l|}{ Biaya Overhead Pabrik: } \\
\hline - Biaya pemeliharaan mesin & $\mathrm{Rp}$ & 3.330 .000 \\
\hline - Biaya penyusutan bangunan & $\mathrm{Rp}$ & 954.000 \\
\hline - $\quad$ Biaya penyusutan mesin & $\mathrm{Rp}$ & 4.500 .000 \\
\hline - $\quad$ Biaya lisrik & $\mathrm{Rp}$ & 1.991 .000 \\
\hline - Biaya bahan penolong & $\mathrm{Rp}$ & 79.853 .420 \\
\hline - $\quad$ Biaya tenaga kerja tidak langsung & $\mathrm{Rp}$ & 24.000 .000 \\
\hline Total & $\operatorname{Rp} 4$ & 104.949.000 \\
\hline Jumlah produk yang dihasilkan & & $9.522 \mathrm{~m}^{2}$ \\
\hline Biaya produksi per $\mathrm{m}^{2}$ & & $\operatorname{Rp} 42.500$ \\
\hline Laba per $\mathrm{m}^{2}$ & & Rp 17.500 \\
\hline
\end{tabular}

Hasil analisis penentuan target costing adalah sebagai berikut. Penentuan Target costing yang digunakan pada penelitian ini meliputi biaya bahan baku, biaya tenaga kerja langsung, dan biaya overhead pabrik yang telah disesuaikan dengan laba yang ingin dicapai oleh perusahaan. Berikut ini dipaparkan biaya target pada CV Multi Bangunan dalam 1 tahun. Setelah ditentukan target costing untuk 1 tahun pada biaya produksi, maka selanjutnya menentukan Value Engeneering pada biaya yang dianggap terlalu besar. Pada penelitian ini value engeneering digunakan alternatif untuk penerapan biaya bahan baku dan biaya bahan penolong. Namun untuk biaya tenaga kerja dan biaya 
overhead pabrik masih menggunakan biaya sesuai dari perusahaan dikarenakan pada biayanya tidak perlu untuk di value engeneering.

Tabel 5. Daftar Target costing CV Multi Bangunan

\begin{tabular}{|c|c|}
\hline Keterangan & Jumlah \\
\hline Target costing Paving Segi- $69.794 \mathrm{~m}^{2} \times \mathrm{Rp} 32.500$ & Rp 318.305.000 \\
\hline Target costing Paving Segi-4 $14.200 \mathrm{~m}^{2} \times \mathrm{Rp} 32.500$ & $\operatorname{Rp} 461.500 .000$ \\
\hline Target costing Paving Conblock Bata $26.190 \mathrm{~m}^{2} \times \mathrm{Rp} 29.250$ & $\mathrm{Rp} 766.057 .500$ \\
\hline Target costing Paving Diamond $9.522 \mathrm{~m}^{2} \times \mathrm{Rp} 39.000$ & $\operatorname{Rp} 371.358 .000$ \\
\hline
\end{tabular}

Tabel 6. Biaya Produksi Alternatif Paving Segi-6

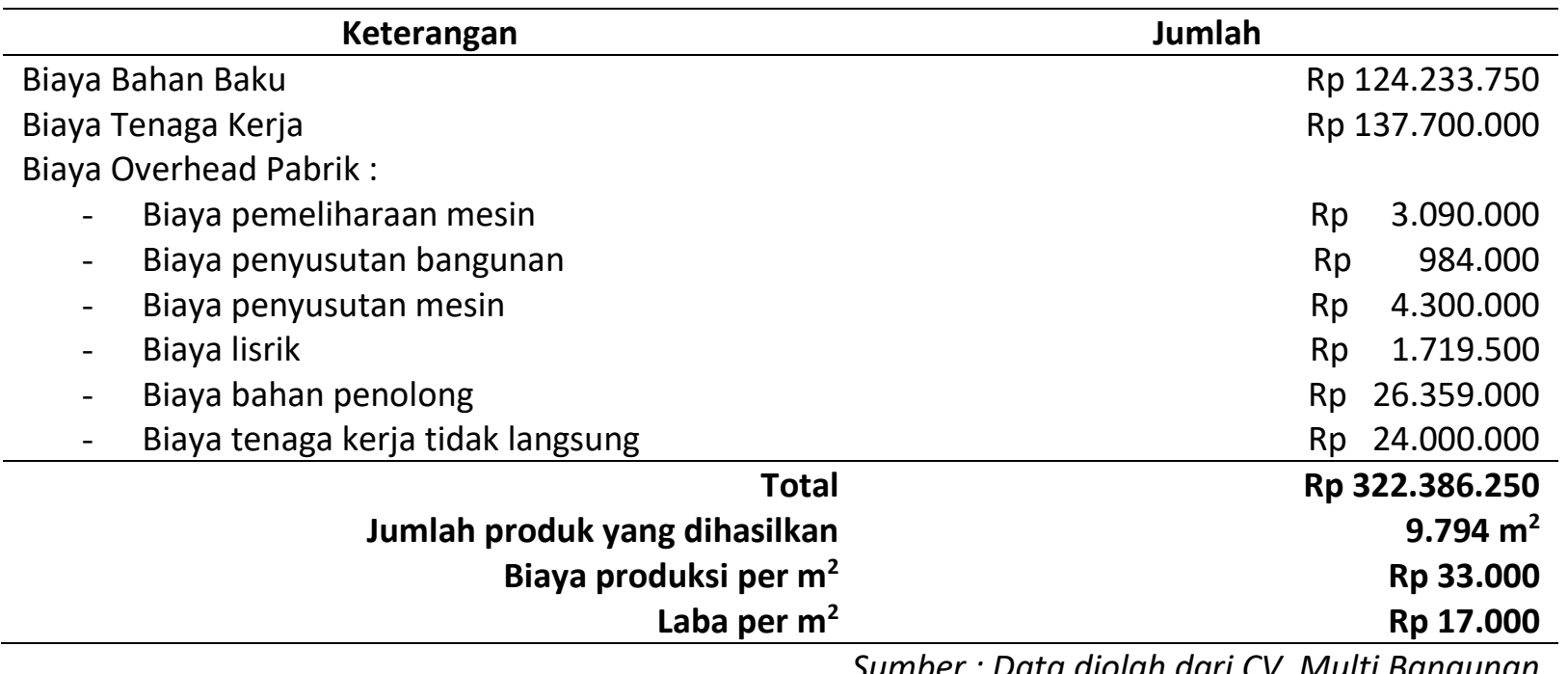

Tabel 7. Biaya Produksi Alternatif Paving Segi-4

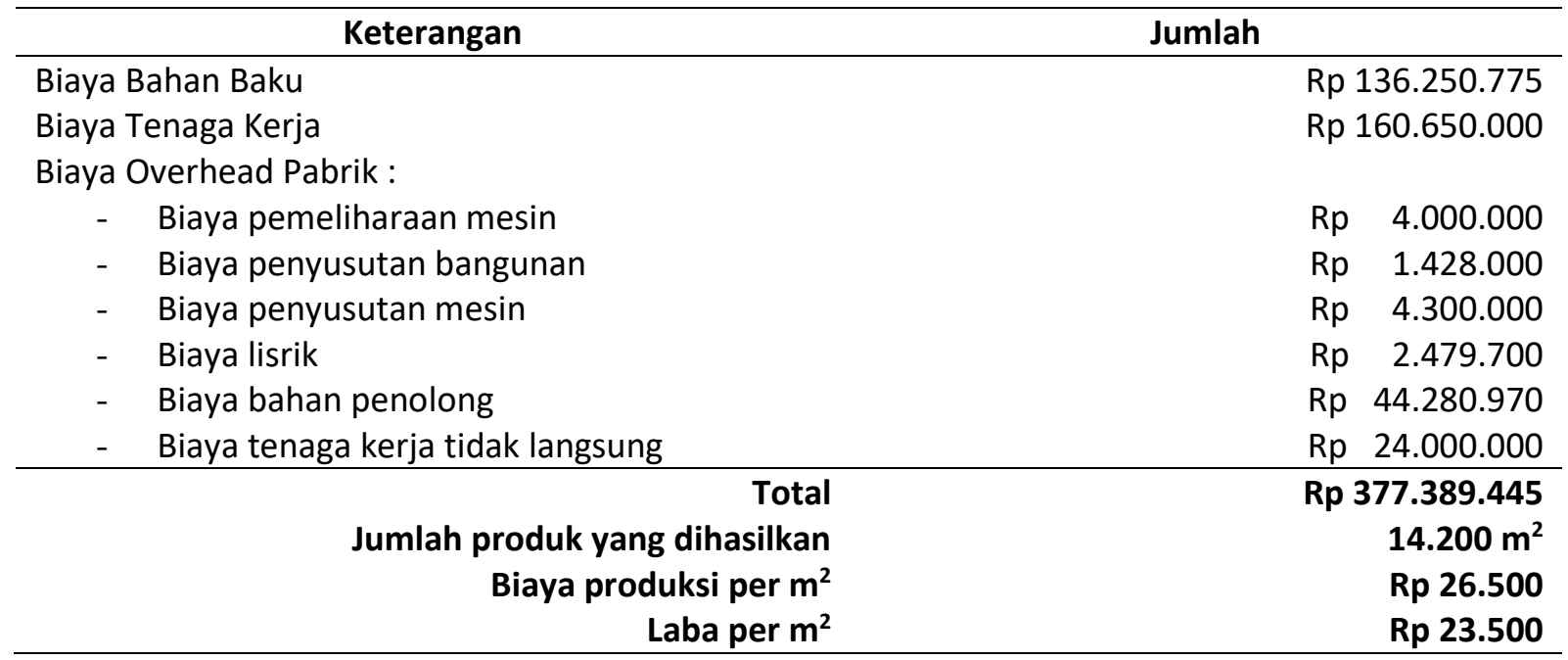

Tabel 8. Biaya Produksi Alternatif Paving Conblock Bata

\begin{tabular}{lc}
\hline \multicolumn{1}{c}{ Keterangan } & Jumlah \\
\hline Biaya Bahan Baku & $\mathrm{Rp} \mathrm{251.606.250}$ \\
Biaya Tenaga Kerja & $\mathrm{Rp} \mathrm{275.400.000}$ \\
$\begin{array}{l}\text { Biaya Overhead Pabrik : } \\
\quad \quad \text { Biaya pemeliharaan mesin }\end{array}$ & $\mathrm{Rp} 4.250 .000$ \\
\hline
\end{tabular}


- Biaya penyusutan bangunan

Rp 2.634 .000

- Biaya penyusutan mesin

Rp $\quad 3.700 .000$

- Biaya lisrik

Rp $\quad 4.126 .800$

- Biaya bahan penolong

Rp 81.684.735

- Biaya tenaga kerja tidak langsung

Rp 24.000 .000

Tota
Jumlah produk yang dihasilkan
Biaya produksi per $\mathrm{m}^{2}$
Laba per $\mathrm{m}^{2}$ Rp 647.401.785

$26.190 \mathrm{~m}^{2}$

Rp 24.700

Rp 20.300

Sumber : Data diolah dari CV. Multi Bangunan

Tabel 9. Biaya Produksi Alternatif Paving Diamond

\begin{tabular}{|c|c|c|}
\hline Keterangan & Jumlah & \\
\hline Biaya Bahan Baku & $\mathrm{Rp}$ & 92.284 .025 \\
\hline Biaya Tenaga Kerja & Rp 1 & 137.700 .000 \\
\hline \multicolumn{3}{|l|}{ Biaya Overhead Pabrik: } \\
\hline - $\quad$ Biaya pemeliharaan mesin & $\mathrm{Rp}$ & 3.330 .000 \\
\hline - Biaya penyusutan bangunan & $\mathrm{Rp}$ & 954.000 \\
\hline - Biaya penyusutan mesin & $\mathrm{Rp}$ & 4.500 .000 \\
\hline - Biaya lisrik & $\mathrm{Rp}$ & 1.991 .000 \\
\hline - Biaya bahan penolong & $\mathrm{Rp}$ & 45.152 .580 \\
\hline - Biaya tenaga kerja tidak langsung & $\mathrm{Rp}$ & 24.000 .000 \\
\hline Total & \multicolumn{2}{|c|}{ Rp 313.911.605 } \\
\hline Jumlah produk yang dihasilkan & \multicolumn{2}{|r|}{$9.522 \mathrm{~m}^{2}$} \\
\hline Biaya produksi per $\mathbf{m}^{2}$ & \multicolumn{2}{|r|}{ Rp 33.000} \\
\hline Laba per $\mathrm{m}^{2}$ & \multicolumn{2}{|r|}{$\operatorname{Rp} 27.000$} \\
\hline
\end{tabular}

Tabel 10. Perbandingan Biaya Menurut Perusahaan, Biaya Alternatif dan Target Costing

\begin{tabular}{|c|c|c|c|}
\hline Jenis Produk & $\begin{array}{l}\text { Biaya Produksi } \\
\text { CV. Multi Bangunan }\end{array}$ & $\begin{array}{l}\text { Biaya Produksi } \\
\text { Alternatif }\end{array}$ & Target costing \\
\hline Paving Segi-6 & Rp 344.772.000 & $\operatorname{Rp} 322.386 .250$ & Rp 318.305.000 \\
\hline Paving Segi-4 & Rp 447.205.730 & Rp 377.389.445 & Rp 461.500 .000 \\
\hline $\begin{array}{l}\text { Paving Conblock } \\
\text { Bata }\end{array}$ & Rp 754.115.066 & $\operatorname{Rp} 647.401 .785$ & $\mathrm{Rp} 766.057 .500$ \\
\hline Paving Diamond & Rp 404.949.020 & Rp 313.911.605 & Rp 371.358 .000 \\
\hline
\end{tabular}

Sumber : Data diolah dari CV. Multi Bangunan

Hasil penelitian menunjukkan bahwa target costing merupakan alternatif yang baik dalam upaya menurunkan atau menekan biaya sesuai dengan penelitian sebelumnya. Keberhasilan metode target costing dalam upaya penurunan biaya perusahaan dengan menggunakan analisis value engineering atau rekayasa nilai produk pada tahap desain dilakukan dengan menekan pemborosanpemborosan pada saat pengadaan barang. Penerapan metode target costing sebagai alternatif direkomendasikan kepada perusahaan agar dapat menekan biaya produksinya guna mendapatkan keuntungan sesuai dengan target laba yang diinginkan perusahaan. Jika perusahaan ingin mendapatkan keuntungan maksimum, perusahaan perlu mengaplikasikan metode tersebut. Namun, semua keputusan adalah hak dari pemilik perusahaan untuk menerapkan metode yang harus digunakannya agar perusahaan dapat mendapatkan keuntungan yang maksimal.

Tabel 11. Perbandingan Laba Sebelum dan Setelah Penerapan Target costing 


\begin{tabular}{|c|c|c|c|c|c|}
\hline Jenis Produk & $\begin{array}{l}\text { Harga Jual } \\
\left(\text { per } \mathrm{m}^{2}\right)\end{array}$ & $\begin{array}{c}\text { Biaya } \\
\text { Produksi } \\
\text { Sebelum TC } \\
\left(\text { per } \mathbf{m}^{2}\right)\end{array}$ & $\begin{array}{l}\text { Laba Sebelum } \\
\left.\text { TC (per } \mathrm{m}^{2}\right)\end{array}$ & $\begin{array}{c}\text { Biaya } \\
\text { Produksi } \\
\text { Setelah TC } \\
\left(\text { per } \mathrm{m}^{2}\right)\end{array}$ & $\begin{array}{l}\text { Laba Setelah } \\
\left.\text { TC (per } \mathbf{m}^{2}\right)\end{array}$ \\
\hline Paving Segi-6 & Rp. 50.000 & $\operatorname{Rp} 35.000$ & $\mathrm{Rp} 15.000$ & Rp 33.000 & Rp 17.000 \\
\hline Paving Segi-4 & Rp 50.000 & Rp 31.000 & Rp 19.000 & Rp 26.500 & Rp 23.500 \\
\hline $\begin{array}{l}\text { Paving Conblock } \\
\text { Bata }\end{array}$ & Rp 45.000 & Rp 28.700 & Rp 16.300 & Rp 24.700 & Rp 20.300 \\
\hline Paving Diamond & Rp 60.000 & $\operatorname{Rp} 42.500$ & Rp 17.500 & Rp 33.000 & Rp 27.000 \\
\hline
\end{tabular}

Biaya target per unit adalah harga target dikurangi penghasilan operasi target per unit (Anugerah et al., 2017; Biodi \& Sanawiri, 2017). Penghasilan operasi target per unit adalah penghasilan operasi yang merupakan sasaran yang ingin diperoleh perusahaan per unit produk atau jasa yang dijual. Biaya target per unit adalah perkiraan biaya jangka panjang. Pada rencana dan kebijakan perusahaan sebelumnya yang sifatnya masih sederhana, tidak terdapat perencanaan manajemen yang baik untuk mengendalikan biaya yang seharusnya dikeluarkan perusahaan. Perusahaan hanya terfokus pada penyediaan bahan baku utama berupa kayu yang harus selalu tersedia ketika perusahaan akan memproduksi produk daun pintu dan kusen tanpa memberi rencana yang tepat bahwa dalam kurun waktu tertentu perusahaan harus memiliki berapa banyak persediaan bahan baku. Kejadian tersebut mengakibatkan tidak terkendalinya biaya-biaya yang seharusnya terjadi. Perusahaan sulit untuk merencanakan banyak atau jumlah keuntungan yang seharusnya menjadi target perusahaan. Begitu pula dalam menentukan harga jual atau dalam perhitungan biaya produksi. Sebelumnya, perusahaan menerapkan kebijakan yang tergolong merupakan metode traditional cost. Perusahaan hanya melihat biaya-biaya yang langsung terjadi ketika melakukan aktivitas produksi, tanpa melihat faktor biaya lain seperti biaya overhead pabrik. Harga produk yang terjadi hanya didapat dari pengakumulasian biaya-biaya yang langsung terjadi. Harga ditentukan sesuai berkembangnya harga di pasaran. Target costing menetapkan bahwa target cost dikurangi dengan marjin laba yang diinginkan. Harga pasar dikendalikan oleh situasi pasar dan laba target ditentukan oleh situasi keuangan suatu usaha dan industri yang dilakukannya (Darmayasa et al., 2019; Febriana, 2020).

Berdasarkan value engineering yang merupakan alat dari metode target costing pada CV Multi Bangunan yang dapat merencanakan cara mendesain ulang biaya sedemikian rupa mulai dari mengganti faktor-faktor yang memengaruhi tingginya biaya yang terjadi pada desain biaya produk sebelumnya. Harga target yang dihitung dengan menggunakan informasi dari pelanggan dan pesaing menjadi dasar untuk menghitung biaya target. Hal ini dapat dijadikan tolak ukur, sehingga perusahaan dapat dengan mudah melihat kemampuan perusahaan menentukan standarisasi harga dan kualitas produk. Melalui pengendalian biaya, penerapan target costing dilakukan dengan mengidentifikasi harga yang diinginkan pasar dan kemudian mendesain produk yang bersedia dibayar oleh pasar tersebut. Dalam hal ini perusahaan ini menetapkan harga jual yang terbaru dan masih berlaku pada pasar dari produk tersebut. Oleh karean itu, dengan metode target costing, perusahaan akan dapat lebih mudah mencapai laba yang ditargetkan. Penerapan target costing adalah hal yang tepat dilakukan dalam mencapai tujuan menurunkan atau menekan biaya produksi (Anugerah et al., 2017; Mahsunah \& Hariyati, 2021). Temuan penelitian diperkuat dengan penelitian sebelumnya yang menyatakan bahwa metode target costing dan berdampak pada peningkatan laba (Darmayasa et al., 2019; Febriana, 2020). Adanya metode target costing laba yang didapatkan lebih optimal karena drifting cost yang dihasilkan lebih kecil (Juwita \& Satria, 2017; Mahsunah \& Hariyati, 2021).

\section{Simpulan}


Berdasarkan hasil analisis, target costing merupakan alternatif yang baik bagi perusahaan CV Multi Bangunan. Hal itu dapat diketahui dari perbedaan jumlah total biaya produksi yang dikeluarkan oleh perusahaan sebelum dan sesudah menggunakan metode target costing pada tahun 2019. Penggunaan metode target costing dalam pengendaliaan biaya produksi merupakan alternatif yang baik dalam menurunkan atau menekan biaya pada CV Multi Bangunan. Dengan menggunakan metode target costing terbukti berdampak positif dalam pencapaian laba perusahaan. Penerapan metode target costing dilakukan dengan cara mengurangi biaya-biaya yang terjadi pada proses produksi, sehingga laba yang ditargetkan oleh perusahaan dapat tercapai. Keterbatasan penelitian ini yaitu objek yang digunakan hanya satu perusahaan. Penelitian selanjutnya mengenai target costing, diharapkan dapat memperluas objek serta menambah atau memvariasikan variabel-variabel yang berpengaruh dalam penggunaan metode target costing, sehinnga dapat menemukan kesimpulan yang lebih baik. Implikasi penelitian ini dapat lebih meningkatkan pengawasan dalam hal pengeluaran biaya-biaya terutama biaya produksi sehingga dalam penggunannya lebih efisien dan dapat meningkatkan laba yang diperoleh perusahaan.

\section{Daftar Pustaka}

Anugerah, E. G., Wahyuni, N. I., \& Mas'ud, I. (2017). Penerapan Target Costing dalam Pengelolaan Biaya Produksi untuk Optimalisasi Laba. E-Journal Ekonomi Bisnis Dan Akuntansi, 4(1), 19. https://doi.org/10.19184/ejeba.v4i1.4554.

Arifin, Z., Indonesia, U. P., \& Kejuruan, S. M. (2012). Implementasi Manajemen Stratejik Berbasis Kemitraan dalam Meningkatkan Mutu SMK (Studi pada SMK Kelompok Teknologi Bidang Otomotif di Kota Yogyakarta). Jurnal Administrasi Pendidikan UPI, 14(1), 60-70. https://doi.org/10.17509/jap.v14i1.6708.

Biodi, M., \& Sanawiri, B. (2017). Analisis Lingkungan Industri Guna Menentukan Business Strategy dalam Rangka Mencapai Keunggulan Bersaing. Jurnal Administrasi Bisnis S1 Universitas Brawijaya, $\quad$ 50(3),

172-181. http://administrasibisnis.studentjournal.ub.ac.id/index.php/jab/article/view/2019/2411.

Darmayasa, G., Sujana, I. N., \& Haris, I. A. (2019). Analisis Penerapan Target Costing dalam Efisiensi Biaya Produksi Batako pada UD Darma Yasa di Desa Panji, Kecamatan Sukasada, Kabupaten Buleleng. Jurnal Pendidikan Ekonomi, 11(2), 383-395. https://doi.org/10.23887/jjpe.v11i2.21511.

Dirgayusa, I. G. P., \& Suardikha, I. M. S. (2017). Pengaruh Komponen Laporan Arus Kas terhadap Return Saham dengan Current Ratio sebagai Variabel Moderasi. E-Jurnal Akuntansi Universitas Udayana, 2(1), 1202-1228.

Febriana, F. A. (2020). The Application of Target Costing in Determining the Selling Price at SuwarSuwir Producers in Jember. Journal of Contemporary Information Technology, Management, and Accounting, 1(2), 72-79.

Hermawan, H. (2018). Analisis Pengaruh Bauran Pemasaran terhadap Keputusan, Kepuasan, dan Loyalitas Konsumen dalam Pembelian Roti Ceria di Jember. Jurnal Manajemen Dan Bisnis Indonesia, 3(2), 1-15. https://doi.org/10.17509/jaset.v3i2.8918.

Hoyt, R. E., \& Liebenberg, A. P. (2011). The Value of Enterprise Risk Management. Journal of Risk and Insurance, 78(4), 795-822. https://doi.org/10.1111/j.1539-6975.2011.01413.x.

Husnan, S. (1993). Dasar-dasar Teori Portofolio: Analisis Sekuritas di Pasar Modal (Edisi 1). UPP-AMP YKPN.

Indriantoro, N., \& Supomo, B. (2014). Metodologi Penelitian Bisnis untuk Akuntansi dan Mananjemen. BPFE.

Juwita, R., \& Satria, M. R. (2017). Penerapan Target Costing dalam Upaya Efisiensi Biaya Produksi untuk Peningkatan Laba Produk. Jurnal Kajian Akuntansi, 1(2), 184-193. https://doi.org/10.33603/jka.v1i2.701.

Kasus, S., Ud, P., \& Cahaya, I. (2021). Efisiensi Biaya Produksi Menggunakan Metode. Journal of Accounting, Finance, and Auditing, 3(2), 1-10. https://doi.org/10.37673/jafa.v3i02.1204. 
Mahsunah, A., \& Hariyati, H. (2021). Peran Penerapan Target Costing dalam Peningkatan Laba UMKM Jurnal Akuntansi AKUNESA, 9(3). https://journal.unesa.ac.id/index.php/akunesa/article/view/11535.

Muhyiddin. (2020). Covid-19, New Normal dan Perencanaan Pembangunan di Indonesia. Jurnal Perencanaan Pembangunan: The Indonesian Journal of Development Planning, 4(2), 240252. https://doi.org/10.36574/jpp.v4i2.118.

Nailufar, F., Sufitrayati, \& Badaruddin. (2018). Pengaruh Laba dan Arus Kas terhadap Kondisi Financial Distress pada Perusahaan Non-Bank yang Terdaftar di Bursa Efek Indonesia. Jurnal Penelitian Ekonomi Akuntansi (JENSI), 2(2), 147-162. https://doi.org/10.21067/jrma.v6i2.4219.

Salam, M. A. K. (2020). Perilaku Produksi di Tengah Krisis Global Akibat Pandemi Covid-19 dan Memanfaatkan Media Online Facebook Sebagai Alternatif Pasar. Ekonomi, Manajemen Dan Akuntansi, 1-21. http://eprints.umsida.ac.id/id/eprint/6834.

Wokas, H., \& Caroline, T. (2016). Analisis Penerapan Target Costing dan Activity-Based Costing sebagai Alat Bantu Manajemen dalam Pengendalian Biaya Produksi Pada Ud. Bogor Bakery. Jurnal Riset Ekonomi, Manajemen, Bisnis Dan Akuntansi, 4(1), 593-603. https://doi.org/10.35794/emba.v4i1.11757. 